\title{
Relationship between hope and fatigue levels in cancer patients
}

\author{
๑1 Melike Çelik ${ }^{1}$, @Özlem Uğur², ĐEzgi Karadağ ${ }^{2}$ \\ ${ }^{1}$ Atatürk Training and Research Hospital, Outpatient Oncology Clinic, İzmir, Turkey \\ ${ }^{2}$ Dokuz Eylül University Faculty of Nursing, Department of Oncology Nursing, İzmir, Turkey
}

Cite this article as: Çelik M, Uğur Ö, Karadağ E. Relationship between hope and fatigue levels in cancer patients. J Health Sci Med 2021; 4(6): 858-864.

\begin{abstract}
Aim: The aim of the present study is; to determine the relationship between fatigue and hope levels in cancer patients.

Material and Method: The study was conducted as a descriptive study. Data were collected using Socio-Demographic Data Qestionnaire, Herth Hope Index, Brief Fatigue Inventory (BFI). The questionnaires were filled outthrough face-to-face interviews.

Results: 213 cancer patients with 50.23\% 21-54 years of age were taken into the study. There was no significant relationship between fatigue status of patients and sociodemographic variables. However, a significant correlation was found between the score of hope and the time after diagnosis $(\mathrm{KW}=2.608 ; \mathrm{p}=0.053)$. In our study, the difference between mean score of hope level and gender, age,marital status, educational status and employment was not statistically significant.

Conclusions: There was a significant negative correlation between fatigue and hope total scores of the patients. This shows us that the management of fatigue during the illness and treatment positively affects the hope and patients are struggling with their disease. it is suggested that the diagnosis of fatigue and hope levels of the patients from the diagnosis and the planning of the attempts to manage them can be suggested.
\end{abstract}

Keywords: Cancer, hope, fatique

\section{INTRODUCTION}

Among the chronic diseases, cancer is one of the major health problem of today. According to the World Cancer Report 2020, there were 19.3 million new cases and 10 million cancer-related deaths worldwide in 2020 (1). Cancer, a major health problem of modern medicine and human, is perceived as a serious and chronic illness, which causes fear, hopelessness, guilt, helplessness, unbearable pain, fatigue, abandonment, death and evokes the feeling and ideas of death, creates anxiety and chaos in patients and their families (2-4). Fatigue is the most common symptom in cancer patients. The prevalence of fatigue associated with cancer and its treatments ranges from 40 to $100 \%(1,4-5)$. Fatigue is among the significant symptoms affecting patients. The fatigue experienced during the diagnosis and treatment process had a negative impact on cancer-fighting power and quality of life of the patients (6).

Cancer is perceived as a disappointing disease due to uncertainties, fears, current and future pains experienced by the individuals (7). The uncertainty might threat one's feelings of hope. It may influence deeply the emotional background of the individual (7). Hope is one of the most important factor that enable to cope effectively with cancer-related loss, uncertainty and suffering (8). Loneliness is the most valuable source for overcoming the stress conditions, such as distress and suffering (7-8). In the literature, disease-related factors in cancer patients (cancer diagnosis, disease progression, time since diagnosis), decreasing functional status and increasing symptom burden were stated as important factors affecting the hope level $(1,9)$. Assessment of fatigue, one of the factors that might affect hope in cancer patients, is important in planning effective interventions. By means of these interventions can structure initiative $s$ improving their adaptation to treatment and quality of life by reducing uncertainties about the future, and problems with disease and treatment, increase treatment compliance, and help the patient maintain his/her hope. The aim of the present study is; to determine the relationship between fatigue and hope levels in cancer patients. 


\section{MATERIAL AND METHOD}

\section{Ethical Considerations}

The study was carried out with the permission of İzmir Katip Çelebi University, Non-Interventional Clinical Investigations Committee of Ethics Committee (Date: 21.01.2016, Decision No: 10), Atatürk Training from the General Secretariat of the Southern Region Public Hospitals Association of İzmir Province (No: 23592379/772.02) and the Research Hospital Oncology Day Care Service. All procedures were carried out in accordance with the ethical rules and the principles of the Declaration of Helsinki. That the validity and reliability of scales in Turkey Çınar et al. (10) and Aslan, Sekmen, Kömürcü \& Özet (19) written consent (11). Patients who met the study criteria were informed about the study and informed consents were obtained from all volunteers.

\section{Design and Samples}

The study was conducted as a descriptive study to examine the relationship between fatigue and hope levels in cancer patients. The study was conducted at the Oncology Outpatient Service of Atatürk Training and Research Hospital, located in a western province of Turkey, between November 2015 - April 2016. Approximately 12,000 patients per year and 60-80 patients per day were admitted to Outpatient Service for treatment. As a selection criterion, patients who were admitted participating in the study, those experienced fatigue within the last 7 days, those over 18 years old, those receiving ambulatory care, those having cancer diagnosis 3 months ago, and those having no perception disorder. Exclusion criterion included patients who had cognitive impairment and mental impairment to disrupt co-operation, and those who did not want to participate in the study. In the G-power statistical program, the required sample size was determined as 210 individuals in a group, at a significance level of 0.05 and $80 \%$ power. The sample size was 213 .

\section{Measurements}

Data were collected using Socio-Demographic Data Questionnaire (Personal Information Form), Herth Hope Index (HHI), Brief Fatigue Inventory (BFI).

Personal Information Form was formed according to the literature by the researchers. The form involved data regarding the age, sex, marital status, educational status, employment, type of cancer, cancer stage, duration of diagnosis and type of treatment of the cases (12-13). There are eight questions in the form.

Brief Fatigue Inventory is a 9-item survey. The form assesses patients' general level of fatigue and its impact on daily activities over the past 24 hours. The BFI uses a scale of 0 , indication 'no fatigue' to 10 , indicating the greatest interference; 0 point: no fatigue; 1-2: minimal fatigue; 3-4: low fatigue; 5-6: moderate fatigue; 7-8: too much fatigue 9-10: severe fatigue. The original scale was developed by Mendoza et al. (14) and Cronbach a value was found as 0.96 . The Turkish Validity and Reliability study of the scale Çinar et al. (2000). Cronbach's alpha value of BFI; It was calculated as 0.97 (10).

Herth Hope Index (HHI) was developed by Dr. Kaye and it is a 12 -item Likert-type scale. The 12 -item, 4-point Likerttype HHI scale assesses the overall hope level of adults. Each item is rated with a score between 1 (I do not agree) and 4 (I strongly agree) and the total score range is between 12 and 48. The higher the score, the higher hope level. Herth index Cronbach's alpha coefficient was 0.98 , in patients with acute disease, 0.96 in patients with chronic disease, and 0.94 in patients in terminal stage (15). The validity and reliability studies of Turkish version of the "Herth Hope Scale" was performed by Aslan, Sekmen, Komurcu and Ozet (11). Cronbach's alpha was 0.75 in the reliability analysis.

There are three subscales within the scope of the scale: "temporary and future", "positive readiness and expectation" and "relations between themselves and their environment". Each sub-dimension consists of 4 questions. Therefore, a participant can score minimum 4 or maximum 16 out of any sub-dimension. The Cronbach alpha values for these three dimensions were $0.77,0.64$ and 0.30 , respectively.

\section{Data Collection}

Data was collected by a researcher from patients who met the criteria for participating in the study and the study was conducted with those who volunteered to participate in the study. The questionnaires were filled out through face-to-face interviews and the information regarding the diagnosis, duration of diagnosis, metastasis, presence of chronic illness, etc. was filled out by using patients' hospital records. The duration of application for a volunteer was determined as 30-35 minutes.

\section{Data Analysis}

The obtained data were analyzed using in IBM SPSS Version 22. Dependent variables; mean fatigue and hope scores of cancer patients in patients. Independent variables; age, gender, educational status, marital status, employment, body mass index, performance status. The socio-demographic characteristics of the sample group were defined by descriptive statistical methods; one-way analysis of variance (Anova), Mann Whitney $U$ test, and Kruskal Wallis test were used to examine the relationship between age, educational status, gender, marital status, employment, cancer type, duration of diagnosis and mean fatigue scores. Pearson correlation analysis was used to examine the relationship between mean hope and fatigue scores of patients, fatigue level and hope. $p$ significance value was determined as $<0.005$. 


\section{RESULTS}

When the socio-demographic characteristics of the patients were examined; $66.7 \%$ were female, $77.0 \%$ were married, $33.3 \%$ were male and the majority were between 21 and 54 years old (50.23\%). Of the patients, $56.3 \%$ were primary school graduates and $42.2 \%$ were unemployed. According to the characteristics of the patients regarding the disease and treatment; $41.7 \%$ were diagnosed with breast cancer, $55.9 \%$ were diagnosed for 12 months or longer, and $93.9 \%$ had received chemotherapy treatment (Table 1).

There was no significant difference between mean scores of patients and gender $(t=0.867, p=0.387)$, age $(t=1.418$, $\mathrm{p}=0.158)$, marital status $(\mathrm{t}=1.513, \mathrm{p}=0.412)$, educational status (KW=1.307, $\mathrm{p}=0.268)$, employment $(\mathrm{KW}=0.061$, $\mathrm{p}=0.941)$, type of cancer $(\mathrm{KW}=0.905, \mathrm{p}=0.513)$, time

\begin{tabular}{|c|c|c|}
\hline Characteristics & Number & $\%$ \\
\hline \multicolumn{3}{|l|}{ Gender } \\
\hline Female & 142 & 66.7 \\
\hline Male & 71 & 33.3 \\
\hline \multicolumn{3}{|l|}{ Marital Status } \\
\hline Married & 164 & 77 \\
\hline Single & 49 & 23. \\
\hline \multicolumn{3}{|l|}{ Age (years) } \\
\hline $21-54$ & 107 & 50.2 \\
\hline $55-80$ & 106 & 49.8 \\
\hline \multicolumn{3}{|l|}{ Educational Status } \\
\hline Illiterate & 6 & 2.8 \\
\hline Literate & 32 & 15 \\
\hline Primary education & 120 & 56.3 \\
\hline High school & 35 & 16.4 \\
\hline College/Faculty & 20 & 9.4 \\
\hline \multicolumn{3}{|l|}{ Employment } \\
\hline Employed & 36 & 16.9 \\
\hline Retired & 87 & 40.8 \\
\hline Unemployed & 90 & 42.2 \\
\hline \multicolumn{3}{|l|}{ Type of cancer } \\
\hline Breast & 89 & 41.7 \\
\hline Colon & 39 & 18.3 \\
\hline Ovary & 19 & 8.9 \\
\hline Pancreas & 11 & 5.1 \\
\hline Stomach & 10 & 4.6 \\
\hline Rectum & 8 & 3.7 \\
\hline Lung & 8 & 3.7 \\
\hline Connective tissue & 5 & 2.3 \\
\hline Other & 24 & 10.7 \\
\hline \multicolumn{3}{|l|}{ Time since diagnosis (months) } \\
\hline$\leq 3$ & 18 & 8.4 \\
\hline $4-6$ & 32 & 15.0 \\
\hline $7-11$ & 44 & 20.7 \\
\hline$\geq 12$ & 119 & 55.9 \\
\hline \multicolumn{3}{|l|}{ Treatment method } \\
\hline Chemotherapy & 200 & 93.9 \\
\hline Chemotherapy and radiotherapy & 13 & 6.1 \\
\hline
\end{tabular}

since treatment $(\mathrm{KW}=1.918, \mathrm{p}=0.128)$ and treatment method $(\mathrm{U}=1.629, \mathrm{p}=0.121)(\mathrm{p}>0.05)$ (Table 2).

According to Table 3, the difference between mean score of hope level and gender $(\mathrm{t}=-237 ; \mathrm{p}=0.813)$, age $(\mathrm{t}=-121 ; \mathrm{p}=0.225)$, marital status $(\mathrm{t}=1,80 ; \mathrm{p}=0.073)$, educational status $(\mathrm{KW}=0.553 ; \mathrm{p}=0.531)$, employment $(\mathrm{KW}=0.184 ; \mathrm{p}=0.832)$, and type of cancer $(\mathrm{KW}=1.089$, $\mathrm{p}=0.372)(\mathrm{p}>0.05)$. Similarly, there was no significant difference between temporary dimension of hope and gender $(t=-0.237 ; p=0.753)$, age $(t=-1.077 ; p=0.378)$, marital status $(\mathrm{t}=1.337 ; \mathrm{p}=0.165)$, educational status $(\mathrm{F}=0.481 ; \mathrm{p}=0.804)$, and employment $\quad(\mathrm{KW}=0.016$; $\mathrm{p}=0.934)(\mathrm{p}>0.05)$. There was no significant difference between temporary subdimension of hope and gender $(\mathrm{t}=-0.027 ; \mathrm{p}=0.979)$, age $(\mathrm{t}=-1.049 ; \mathrm{p}=0.189)$, marital status ( $\mathrm{t}=1.357 ; \mathrm{p}=0.086)$, educational status (KW $=2.022 ; \mathrm{p}=0.083)$ and employment $(\mathrm{KW}=0.328$; $\mathrm{p}=0.586)(\mathrm{p}>0.05)$. There was no significant difference between relations with themselves and those around subdimension of hope and gender ( $t=-0.220 ; \mathrm{p}=0.985)$, age $(\mathrm{t}=-0.993 ; \mathrm{p}=0.355)$, marital status $(\mathrm{t}=2.041 ; \mathrm{p}=$ $0.178)$, educational status $(\mathrm{KW}=1.579 ; \mathrm{p}=0.368)$, and employment $(\mathrm{KW}=0.110 ; \mathrm{p}=0.754) \quad(\mathrm{p}>0.05)$. There was a significant difference between time after diagnosis and mean total score of hope ( $\mathrm{KW}=2.608 ; \mathrm{p}=0.053$ ) $(\mathrm{p}<0.05)$. Accordingly, the total hope score of patients with diagnosis period of 4-6 months was statistically higher than others. The difference between the time after diagnosis and temporary subdimension of hope $(\mathrm{KW}=1.670 ; \mathrm{p}=0.175)$, positive readiness $(\mathrm{KW}=2.367$; $\mathrm{p}=0.721)$, and relations with themselves and those around $(\mathrm{KW}=1.295 ; \mathrm{p}=0.175)(\mathrm{p}>0.05)$. There was a significant difference between treatment method and time after diagnosis and mean total score of hope level $(\mathrm{U}=-2.534 ; \mathrm{p}=0.011)$. While there was no significant association between treatment method and temporary subdimension of hope $(\mathrm{U}=-1.128 ; \mathrm{p}=0.259)$, a negative correlation was detected between positive readiness $(\mathrm{U}=-2.535 ; \mathrm{p}=0.011)$ and relations with themselves and those around $(\mathrm{U}=-3.779 ; \mathrm{p}=0.00)(\mathrm{p}<0.05) \quad($ Table 3). When the correlation between total score of brief fatigue inventory and general total score of Hert hope index and subdimensions was analyzed, a statistically negative and significant association was detected (Table 4). Although not shown in the table; the mean score of brief fatigue inventory of the patients was $43.22 \pm 25.94$ and the general score of hope scale was $43.98 \pm 4.20$. When the subdimensions of hope was examined, mean score of temporary subdimension of hope was $16.66 \pm 2.10$, mean score of positive readiness subdimension was $14.72 \pm 1.10$, and mean score of relations with themselves and those around was $12.60 \pm 1.01$. 


\begin{tabular}{|c|c|c|c|c|c|}
\hline \multirow{2}{*}{ Characteristics } & \multicolumn{3}{|c|}{ Total Mean Score of Brief Fatigue Inventory } & \multirow{2}{*}{$\mathbf{t} / \mathrm{KW}$} & \multirow{2}{*}{$\mathbf{p}$} \\
\hline & $\mathbf{n}$ & $\mathbf{X}$ & SD & & \\
\hline Gender & & & & $\mathrm{t}=0.87$ & $\mathrm{p}=.387$ \\
\hline Female & 142 & 39.88 & 23.69 & & \\
\hline Male & 71 & 36.94 & 22.70 & & \\
\hline Age (years) & & & & $\mathrm{t}=1.41$ & $\mathrm{p}=.158$ \\
\hline $21-54$ & 107 & 41.19 & 21.88 & & \\
\hline $55-80$ & 106 & 36.67 & 24.35 & & \\
\hline Marital status & & & & $\mathrm{t}=1.51$ & $\mathrm{p}=.412$ \\
\hline Married & 164 & 40.22 & 23.39 & & \\
\hline Single & 49 & 34.48 & 22.90 & & \\
\hline Educational status & & & & $\mathrm{KW}=1.31$ & $\mathrm{p}=.268$ \\
\hline Illiterate & 6 & 54.02 & 21.45 & & \\
\hline Literate & 32 & 35.90 & 22.69 & & \\
\hline Primary education & 120 & 40.47 & 23.17 & & \\
\hline High school & 35 & 37.24 & 26.10 & & \\
\hline University & 20 & 32.65 & 19.77 & & \\
\hline Employment & & & & $\mathrm{KW}=0.06$ & $\mathrm{p}=.941$ \\
\hline Employed & 36 & 39.47 & 22.42 & & \\
\hline Retired & 87 & 39.02 & 24.07 & & \\
\hline Unemployed & 90 & 38.05 & 23.03 & & \\
\hline Type of cancer & & & & $\mathrm{KW}=0.91$ & $\mathrm{p}=.513$ \\
\hline Breast & 89 & 37.63 & 23.96 & & \\
\hline Colon & 39 & 41.20 & 27.13 & & \\
\hline Ovary & 19 & 42.37 & 18.61 & & \\
\hline Pancreas & 11 & 40.79 & 19.43 & & \\
\hline Stomach & 10 & 45.40 & 12.61 & & \\
\hline Rectum & 8 & 28.50 & 24.40 & & \\
\hline Lung & 8 & 51.75 & 27.33 & & \\
\hline Connective tissue & 5 & 28.60 & 18.99 & & \\
\hline other & 24 & 38.48 & 23.14 & & \\
\hline Time since diagnosis (months) & & & & $\mathrm{KW}=1.92$ & $\mathrm{p}=.128$ \\
\hline$\leq 3$ & 18 & 28.40 & 19.87 & & \\
\hline $4-6$ & 32 & 35.12 & 23.26 & & \\
\hline $7-11$ & 44 & 42.68 & 20.88 & & \\
\hline$\geq 12$ & 119 & 40.11 & 24.37 & & \\
\hline Treatment method & & & & $\mathrm{U}=1.63$ & $\mathrm{p}=.121$ \\
\hline Chemotherapy & 200 & 38.81 & 23.83 & & \\
\hline Chemotherapy and Radiotherapy & 13 & 45.39 & 13.21 & & \\
\hline
\end{tabular}

\section{DISCUSSION}

Cancer patients suffer from limitations in prognosis and treatment. These limitations can often lead to the disappearance of the joy of life (3). In this study, there was no significant difference between mean fatigue scores and mean score of gender, age, marital, educational and employment status of the patients. Although there was no statistical difference, it was found that mean fatigue scores of female and married patients were higher than males and singles, respectively. The reason for this may be due to the high number of females and married individuals taken into the study. In the literature, it was generally stated that mean fatigue scores of females and married individuals were higher (16). This finding may be derived from the several domestic responsibilities of women because of the traditional family structure in Turkey. Although there was no statistically significant difference in the study, mean fatigue scores of the individuals graduated from primary school. Our findings are consistent with the literature (16-17).

In the study, the difference between mean fatigue score and the cancer type, the time after the diagnosis and mean scores of treatment methods of the patients were not significant. Our finding was consistent with finding Kagure (17). Although there was no statistically significant difference, it was determined that mean fatigue scores of patients with lung cancer were higher. This is due to cough, respiratory distress, and nutritional problems in the patients with lung cancer, which negatively affects the quality of life of the person (16). Cancer-related fatigue 
Table 3. Comparison of mean scores of hope levels and socio-demographic and disease-related characteristics of patients

Sub-dimensions of hope level

\begin{tabular}{|c|c|c|c|c|c|c|c|c|c|c|c|c|c|c|c|c|}
\hline \multirow[t]{2}{*}{ Characteristics } & \multicolumn{4}{|c|}{ Total score } & \multicolumn{4}{|c|}{$\begin{array}{l}\text { Temporary dimension of } \\
\text { hope }\end{array}$} & \multicolumn{4}{|c|}{ Positive readiness } & \multicolumn{4}{|c|}{$\begin{array}{l}\text { Relations with themselves } \\
\text { and those around }\end{array}$} \\
\hline & $\mathbf{n}$ & $\mathbf{X}$ & Sd & $\mathbf{p}$ & $\mathbf{n}$ & $\mathbf{X}$ & Sd & $\mathbf{p}$ & $\mathbf{n}$ & $\mathbf{X}$ & SS & $\mathbf{p}$ & $\mathbf{n}$ & $\mathbf{X}$ & Sd & p \\
\hline \multicolumn{17}{|l|}{ Gender } \\
\hline Female & 142 & 44.17 & 3.54 & \multirow{2}{*}{.813} & 142 & 14.14 & 1.93 & \multirow{2}{*}{.753} & 142 & 14.59 & 1.60 & \multirow{2}{*}{.979} & 142 & 15.44 & 0.93 & \multirow{2}{*}{.985} \\
\hline Male & 71 & 44.29 & 3.81 & & 71 & 14.23 & 1.98 & & 71 & 14.60 & 1.88 & & 71 & 15.47 & 0.87 & \\
\hline \multicolumn{17}{|l|}{ Age (years) } \\
\hline $21-54$ & 107 & 43.89 & 3.84 & \multirow{2}{*}{.225} & 107 & 14.04 & 1.97 & \multirow{2}{*}{.378} & 107 & 14.47 & 1.71 & \multirow{2}{*}{.189} & 107 & 15.38 & 0.96 & \multirow{2}{*}{.355} \\
\hline $55-80$ & 106 & 44.50 & 3.41 & & 106 & 14.28 & 1.92 & & 106 & 14.71 & 1.69 & & 106 & 15.50 & 0.87 & \\
\hline \multicolumn{17}{|l|}{ Marital status } \\
\hline Married & 164 & 44.45 & 3.55 & \multirow{2}{*}{.073} & 164 & 14.30 & 1.90 & \multirow{2}{*}{.165} & 164 & 14.68 & 1.68 & \multirow{2}{*}{.086} & 164 & 15.51 & 0.83 & \multirow{2}{*}{.178} \\
\hline Single & 49 & 43.40 & 3.78 & & 49 & 13.87 & 1.82 & & 49 & 14.31 & 1.71 & & 49 & 15.24 & 1.13 & \\
\hline \multicolumn{17}{|c|}{ Educational status } \\
\hline Illiterate & 6 & 46.02 & 1.24 & & 6 & 14.83 & 1.16 & & 6 & 15.68 & 1.51 & & 6 & 15.50 & 1.22 & \\
\hline Literate & 32 & 43.85 & 3.51 & & 32 & 14.33 & 1.34 & & 32 & 14.50 & 1.51 & & 32 & 15.17 & 1.09 & \\
\hline Primary school & 120 & 44.41 & 3.53 & .531 & 120 & 14.14 & 2.09 & .804 & 120 & 14.74 & 1.57 & .083 & 120 & 15.54 & 0.83 & .368 \\
\hline High school & 35 & 43.61 & 4.48 & & 35 & 14.35 & 1.82 & & 35 & 13.99 & 2.29 & & 35 & 15.27 & 1.04 & \\
\hline University & 20 & 44.06 & 3.24 & & 20 & 13.83 & 1.71 & & 20 & 14.60 & 1.47 & & 20 & 15.63 & 0.62 & \\
\hline Employment * & & & & & & & & & & & & & & & & \\
\hline Employed & 36 & 44.48 & 3.35 & & 34 & 14.25 & 1.72 & & 36 & 14.70 & 1.65 & & 36 & 15.53 & 0.77 & \\
\hline Retired & 87 & 44.08 & 3.53 & .832 & 85 & 14.14 & 2.02 & .934 & 87 & 14.54 & 1.63 & .754 & 87 & 15.41 & 0.92 & .586 \\
\hline Unemployed & 88 & 44.34 & 3.78 & & 88 & 14.23 & 1.93 & & 90 & 14.61 & 1.81 & & 90 & 15.50 & 0.91 & \\
\hline Type of cancer & & & & & & & & & & & & & & & & \\
\hline Breast & 89 & 44.16 & 3.36 & & 89 & 14.20 & 1.79 & & 89 & 14.58 & 1.56 & & 89 & 15.39 & 0.95 & \\
\hline Colon & 39 & 43.77 & 3.99 & & 39 & 14.10 & 2.01 & & 39 & 14.47 & 2.04 & & 39 & 15.31 & 0.97 & \\
\hline Ovary & 19 & 44.00 & 3.87 & & 19 & 14.05 & 1.78 & & 19 & 14.37 & 2.01 & & 19 & 15.58 & 0.69 & \\
\hline Pancreas & 11 & 41.98 & 4.21 & & 11 & 13.18 & 1.89 & & 11 & 13.80 & 1.89 & & 11 & 15.00 & 1.34 & \\
\hline Endometrium & 10 & 44.80 & 3.58 & .372 & 10 & 14.40 & 1.58 & .788 & 10 & 14.80 & 1.69 & .416 & 10 & 15.60 & 0.97 & .446 \\
\hline Rectum & 8 & 46.00 & 2.88 & & 8 & 14.50 & 2.39 & & 8 & 15.50 & 0.76 & & 8 & 16.00 & 0.00 & \\
\hline Lung & 8 & 44.87 & 3.64 & & 8 & 14.37 & 2.20 & & 8 & 14.62 & 1.51 & & 8 & 15.87 & 0.35 & \\
\hline $\begin{array}{l}\text { Connective } \\
\text { tissue }\end{array}$ & 5 & 44.40 & 3.91 & & 5 & 14.80 & 1.30 & & 5 & 14.00 & 1.87 & & 5 & 16.60 & 0.89 & \\
\hline Other & 24 & 45.10 & 3.58 & & 24 & 14.46 & 2.19 & & 24 & 15.12 & 1.28 & & 24 & 16.62 & 0.79 & \\
\hline Time after dia & is $(\mathrm{mc}$ & nths) & & & & & & & & & & & & & & \\
\hline$\leq 3$ & 18 & 44.84 & 3.17 & & & 14.72 & 1.45 & & & 14.58 & 1.56 & & & 15.54 & 0.60 & \\
\hline $4-6$ & 32 & 45.67 & 2.50 & 053 & & 14.71 & 1.65 & & & 15.31 & 0.86 & & & 15.66 & 0.60 & \\
\hline $7-11$ & 44 & 44.09 & 3.59 & .0JJ & & 14.03 & 1.59 & .11 & & 14.52 & 1.70 & & & 15.53 & 0.96 & \\
\hline$\geq 12$ & 119 & 43.76 & 3.87 & & & 14.03 & 2.075 & & & 14.43 & 1.84 & & & 15.34 & 0.99 & \\
\hline Treatment metho & & & & & & & & & & & & & & & & \\
\hline Chemotherapy & 200 & 43.54 & 3.15 & & 200 & 43.54 & 3.15 & & & 38.70 & 3.35 & .011 & 200 & 36.60 & 3.81 & \\
\hline $\begin{array}{l}\text { Chemotherapy } \\
\text { and } \\
\text { radiotherapy }\end{array}$ & 13 & 28.20 & 3.44 & .011 & 13 & 24.16 & 1.06 & .259 & & 24.16 & 1.06 & & 13 & 24.16 & 1.06 & .000 \\
\hline
\end{tabular}

Table 4. Relationship between mean score of brief fatigue inventory and hope and subdimensions of hope

Total Score of Brief Fatigue Inventory

Relationship between brief fatigue inventory and hope and subdimensions of hope

$\mathrm{r}^{*} \quad \mathrm{p}^{* *}$

Total Score of Herth Hope Index

Temporary Subdimension of Hope

$-.41$

$<.001$

Total Score of Positive Readiness

$-.42$

$<.001$

Relations with themselves and those around

$-.27$

$<.001$

${ }^{*} \mathrm{r}=$ Pearson correlation analysis was used as variables met the normal distribution hypothesis. ${ }^{* *}$ Correlation was significant at the level 0.01 (2-tailed). 
is associated with the duration of diagnosis and showed elevation after the treatments. Although patients receiving both chemotherapy and radiotherapy may be expected to experience more fatigue, the difference between treatment and mean fatigue scores was not significant (18).

Cancer patients pass the adaptation process to their diseases with various reactions. Positive responses influence the healing process positively (3). In our study, the difference between mean score of hope level and gender, age, marital status, educational status and employment was not statistically significant. In literature, although women are reported to be more disadvantaged than males in situations, such as mood disorders, depression and self-annihilation (19), there are also studies indicating no gender difference in terms of hope (16-17). Our findings are consistent with the literature (20). This suggests that the negative healthrelated changes reduce the hope level of young patients, and they are easily affected by the negative interactions in their environment (21).

The difference between cancer type and total score of hope level was not significant. This finding might be related to the cancer type and stage of the individuals. It is noteworthy that the five-year survival rates of cancer types are relatively high. Five-year survival rate is $87 \%$ for breast cancer, 59\% for bowel cancer, and $65 \%$ for colon cancers (22-23). Moreover Costa et al. (24) found that patients with breast cancer had higher total hope scores, and it was stated that high hope levels helped individuals to flow the changes in their values and caused the questioning of the meaning of life by providing internal self-motivation. However, the data regarding the cancer stages were not obtained from the patient records. This is the limitation of our study. There was a significant difference between the time after the diagnosis and mean total hope score and the subdimension of positive readiness $(\mathrm{p}<0.05)$. However, it was determined that total and subdimension scores of hope were lower as the duration of diagnosis was prolonged. It might be concluded that the hope of the cancer patients decreases as the duration of diagnosis and treatment increases. According to the literature, fear and uncertainty caused by cancer, long treatment period and uncontrollable side effects constituted a risk factor in terms of hopelessness, future anxiety and negative thoughts, depression and hopelessness (2526). Likewise, in the same study, it was found that the scores of temporary subdimension of hope in patients with duration of diagnosis $\leq 3$ months, mean scores of positive readiness and relationship with themselves and their environment in patients with duration of diagnosis between 4-6 months were found to be higher. This shows us that patients maintain positive relationships with their environment to maintain their hope during their disease.
The scores of positive readiness involving fatigue score and hope subdimensions, and the subdimension scores of relationship with themselves and their environment were found to be higher. The fatigue levels of patients were low $($ mean $=43.229)$ and general hope score was high (mean=432). As patients' fatigue reduce, hope increases. In the literature, while a similar association was found between fatigue and hope (26). In addition, we found a weak negative correlation between subdimensions of positive readiness and relationship between themselves and their environment. The result shows that individuals who are struggling with cancer have confidence to the treatments and maintain their hopes for recovery. In addition, new therapies related to cancer and treatment cause the maintenance of hope feeling for recovery in individuals. This shows us that the management of fatigue during the illness and treatment positively affects the hope and patients are struggling with their disease (27).

\section{Study Limitations}

The study was done in a single hospital, the number of samples, and the fact that the sample of the patient group was not able to reach the cancer stage data was a limitation.

\section{CONCLUSION}

The study was a significant negative correlation between fatigue and hope subdimensions. It was determined that the duration of diagnosis and the treatment method affected the hope and fatigue scores. At the end of this study, it is recommended to perform the fatigue assessment of patients as from the diagnosis, to inform the patients regarding fatigue management, to structure attempts for increasing the hope levels and to plan interventions for developing the coping-skills of patients with disease.

\section{ETHICAL DECLARATIONS}

Ethics Committee Approval: The study was carried out with the permission of İzmir Katip Çelebi University, Non-Interventional Clinical Investigations Committee of Ethics Committee (Date: 21.01.2016, Decision No: 10).

Informed Consent: All patients signed the free and informed consent form.

Referee Evaluation Process: Externally peer-reviewed.

Conflict of Interest Statement: The authors have no conflicts of interest to declare.

Financial Disclosure: The authors declared that this study has received no financial support.

Author Contributions: All of the authors declare that they have all participated in the design, execution, and analysis of the paper, and that they have approved the final version. 


\section{REFERENCES}

1. Sung H, Ferlay J, Siegal RL, et al. Global cancer statistics 2020: GLOBOCAN estimates of incidence and mortality worldwide for 36 cancers in 185 countries. CA: A Cancer J Clin 2020; 71: 20949.

2. Ministry of Health, Directorate General of Public Health, Department of Cancer. http://kanser.gov.tr/daire-faaliyetleri/ kanser-istatistikleri/ $860-$ yeni-d\%C3\%BCnya-kanseristatistikleri-yay\% C4\% B 1 nland \% C 4\% B 1.html\#sthash. rVNq4ChN.dpuf Erişim tarihi: 15.12.2020

3. van Baalen NC, Grypdonck M, van Hecke A, Verhaeghe S. Associated factors of hope in cancer patients during treatment: A systematic literature review. J Adv Nurs 2019; 76: 1520- 37.

4. National Comprehensive Cancer Network. NCCN Clinical Practice Guideline in Oncology TM: Cancer-related fatigue. 2017, http://www.nccn.org/professionals/physician_gls/PDF/fatigue. pdf. date of access: 14.12.2017.

5. Tarakçığlu, ÇGH. Symptom Management in Oncology Nursing. Gümüşhane University Journal of Health Sciences 2016; 5: 93100 .

6. Spahrkäs SS, Looijmans A., Sanderman R, Hagedoorn M. Beating cancer-related fatigue with the Untire mobile app: Results from a waiting-list randomized controlled trial. Psycho-Oncology 2020; 29: $1823-34$.

7. Özdaş, T. and Olgun, N. Hopelessness Level and Affecting Factors of Patients with Bone Marrow Transplantation. HSP 2015; 2: 12 21.

8. Mahendran R, Chua SM, Lim HA, et al. Biopsychosocial correlates of hope in Asian patients with cancer: a systematic review. BMJ Open 2016; 6: 12087.

9. Mohandas H, Jaganathan SK, Mani MP, Ayyar M, Rohini Thevi GV. Cancer-related fatigue treatment: An overview. J Cancer Res Ther 2017; 13: 916-29.

10. Çınar S, Sezerli M, Sarsmaz N, Menteş AÖ. Hemodiyaliz akut yorgunluk sendromuna neden olabilir mi? Hemşirelik Forumu Derg 2000; 3: 28-33.

11. Aslan Ö, Sekmen K, Kömürcü Ş, Özet A. Hope in cancer patients. Journal of Cumhuriyet University School of Nursing 2007; 1: 1824.

12. Tarhan, S. and Bacan, H. Adaptation of Continuous Hope Scale to Turkish: Validity and reliability study. J Happiness Well-Being 2015; 3: 1-14.

13. Özdelikara, A. The effect of reflexology on nausea, vomiting and fatigue in breast cancer patients. Asia Pac J Oncol Nurs 2017; 4: 241- 9 .

14. Mendoza TR, Wang XS, Cleeland, CS, et al. Therapid assessment of fatigue severity in cancer patients. Cancer 1999; 85: 1186- 96.

15. Herth, K. Abbreviated instrument to measure hope: develeopment and psychometric evaluation. JAN 1992; 17: 1251-9.

16. Wright F, Kober MK, Cooper AB, et al. Higher levels of stress and different coping strategies are associated with greater morning and evening fatigue severity in oncology patients receiving chemotherapy. Supportive Care in Cancer 2020; 28: 4697-706.

17. Kogure E, Hara T, Ishii T, Maeda, M. Changes in fatigue and physical function with age for patients with gastrointestinal cancer in the perioperative period:a comparison between older and young patients. J Phys. Ther 2017; 29: 2004-8.

18. South Florida Cancer Association. EPEC. Education in palliative and end-of-life care for oncology. Self-Study Module 3k: Fatigue. http://www.egdutton2.com/resources- for/hp/education/epeco/ self-study/module-3/MS_81849.pdf access15.12.2017

19. Baczewska B, Block B, Kropornicka B, et al. Hope in advanced cancer patients in the terminal phase of neoplastic disease and stability of basic mood. J Clin Med 2020; 9: 3550;
20. Ginter CA. The day you lose your hope is the day you start to die": Quality of life measured by young women with metastatic breast cancer. J Psychosoc Oncol 2020; 38: 418- 34.

21. Baczewska B, Block B, Kropornicka B, et al. Hope in hospitalized patients with terminal cancer. Int J Environ Res Public Health 2019; 16: 3867.

22. Quaresma M, Coleman MP, Rachet B. 40-year trends in an index of survival forall cancers combined and survival adjusted for age and sex for each cancer in England and Wales, 1971-2011: a population-based study. Lancet 2015; 385: 1206-18.

23. White A, Joseph D, Rim SH, Johnson CJ, Coleman MP, Allemani C. Colon cancer survival in the United States by race and stage (2001-2009): Findings from the CONCORD-2 study. Cancer 2017; 24: 5014-36.

24. Costa DT, Silva DMRD, Cavalcanti IDL, Gomes ET, Vasconcelos JLA, Carvalho MVG. Religious/spiritual coping and level of hope in patients with cancer in chemotherapy. Rev Bras Enferm 2019; 72:640-5.

25. Ozen B, Ceyhan Ö, Büyükçelik A. Hope and perspective on death in patients with cancer. Death Studies 2019; 44: 412- 8.

26. Bener A, Alsulaiman R, Doodson L, Agathangelou T. Depression, hopelessness and social support among breast cancer patients: in highly endogamous population. Asian Pac J Cancer Prev 2017; 18: 1889-96.

27.Herbrand KM., Silverman JM. A randomized pilot study of patient-preferred live music addressing fatigue, energy, and pain in adults on a medical oncology/hematology unit. Psychol Music 2020; 1-12. 